\title{
Aplicação das ações preconizadas pelo Ministério da Saúde para o parto humanizado em um hospital de Santa Catarina
}

\author{
Application of Ministry of Health guidelines for humane \\ childbirth in a hospital in Santa Catarina, Brazil
}

Adriana Elias dos Reis 1 Zuleica Maria Patrício 2

\footnotetext{
${ }^{1}$ Un iversid ade do Sul de Santa Catarina. Av. José Acácio Moreira 787, 88704-900, Tubarão SC. adrianar@unisul.br

2 Un iversid ade do Sul de Santa Catarina. zucamp@hotmail.com
}

Abstract The change in the scenary from home birth to the hospital has created anotherculture in the care and attendance for woman in labor, leading to a depreciation of the potencial of the human care, in your cultu ral and affective characteristics and generating discomfort and even aggrava ting the woman's health and her infant. Looking upon this reality, the Health Departament created gruidelines to help the actions of health teams in the process of birth. The focus of this study was to analyze, in a qualitative way, the application of those actions in a obstetric center of a hospital in the St a te of Santa Catarina. This rese a rch had as pa rticipants eleven women in labor, their infants and their companions and the health professionals that assisted those women. The analysis of the data, ra ised through the techniques of participant comment, interview and documentary analysis, showed limitations of the healty team to incorporate the guidelines in a daily basis routine attendance as well as of the pregnants women and companions in stimulating these practices, especially for the lack of knowledge of your rights. This reinforces the importance of those guidelines been worked during the prenatal of preganant women with their relatives.

Key words Humanized childbirth, Humanization of the hospital assistance, Collective health
Resumo A mudança do cenário domiciliar do nascimento pa ra o hospitalar fez emergir nova cultura de atendimento à mulher parturiente, provocando desvalorização do potencial do cuidado humano, em suas caracterís ticas cultu rais e afetivas, e gerando desconforto e até agravos à saúde da mulher e do seu recém-nascido.Tendo em vista essa realidade, o Ministério da Saúde criou diretrizes para orientar as ações das equipes de saúde no pro ces so de parir. O fo co deste estudo foi analisar, de forma qualitativa, a aplicação dessas ações pre conizadas em um cen tro obstétrico de um hospital do Estado de Santa Catarina. Participaram como sujeitos do estudo onze parturien tes e seus recém-nascidos e acompanhantes $e$ os profissionais da equipe de saúde que atenderam essas mulheres. A análise dos dados, levantados por observação participante, entrevista e análise documental, mostrou limitações da equipe de saúde pa ra incorporar as referidas diretrizes no cotidiano da assistência, bem como das gestantes e acompanhantes em estimular essa prática, especialmentepelo desconhecimen to que têm de seus direitos. Is to reforça a importância dessas diretrizes serem trabalhadas no pré-natal junto às gestantes e seus familiares.

Palavras-chave Pa ro humanizado, Humanização da assistência hospitalar, Saúde coletiva 


\section{Apresentação}

A assistência à saúde da parturiente vem sen do discutida na perspectiva de tornar o processo de parir e nascer um con texto de promoção à saúdedamulh er e de seu recém-nascido Inibir os excessos de partos cirúrgicos é apenas uma das metas dessa assistência que deverá se consolidar, se construída com foco na atenção mais humanizada.

Os profissionais da equipe de saúde que aten dem essa população têm sido apontados como importantes mediadores no trabalho de tornar tal proposta uma realidade. Esse estu do valida essa importância e mostra que, sem a participação efetiva da mulh er e de seu acompanhantecomo agen tes que conhecem seus direitos e se envolvem nas decisões referen tes a sua própria vida, não será possíved alcançar as ex pect a tivas doMinistério da Saúde.

A atenção à mulher parturien te vem sendo difundida em todos os níveis de atenção à saúde na rede pública, pois a humanização do a tendimento aos usuários do Sis tema Único de Saúde (SUS) é meta do Ministério da Saúde. Para alcançá-la foram criados alguns incentivos como: Programa de Humanização do PréNatal e do Nascimen to, a constituição de Comitê de Humanização dos Serviços de Saúde e o Prêmio Naci onal Profe s s orGalba de Ara új o.

Resultados desses incentivos já se fazem a nunciar na rede pública, por exemplo, os índices de 1999: "Do total de partos realizados (...) 2 milhões e 600 mil foram normais e 660 mil cesáreas" (Tanaka apud Rede Nacional Feminista de Saúde e Direitos Reprodutivos, 2002).

Pa ra o Mnistério da Saúde (Brasil, 2001), a grande con quista está em disseminar a prática de partos naturais em detrimen to do número de cesarianas. Acompanha essa expectativa de incrementar o parto natu ral o rompimento das práticas desenvolvidas no processo do nascimento, ainda predominantemente centradas na cultura do nascimen to segundo a tradição médica, lon ge de con si derar a participação afetiva e cultu ral da parturiente.

A humanização do parto promove situações que inibem o mal-estar da mulher e também redu zem riscos para ela e para o bebê, ao mesmo tem po em que possibilita conforto e seg u rança para o acompanhante. De acordo com esse entendimento, a Organização Mundial da Saúde elaborou o documento denominado Assistência ao Parto Normal, no qual estabelece ações direcionadas ao atendimen to das necessidades básicas damulh er e de sua família.

Segundo o Ministério da Saúde, a implem entação ou ex tinção dessas ações está diret amente relacion ada à conscientização dos profis si onaisem recon h ecer que a mulh eréa principal protagonista do processo de parto, devendo ter sua dignidade, individualidade e valores respeit ados (Brasil, 2001).

Nesta perspectiva, foi que se desenvo lveu o estudo com o objetivo de analisar a aplicação das ações preconiz adas pelo Mnistério da Saúde para o parto humanizado em um Centro Obstétrico de um Hospital-Geral do sul de Santa Catarina.

Como referencial para olhar estarealidade, foramutiliz adas as seg u in tes categorias precon izadas pelo Ministérioda Saúde para a humanização da assistência: a) práticas consideradas ú teis e que devem ser estimuladas; b) práticas claram en te prejudiciais ou ineficazes e que devem ser eliminadas; c) práticas em relação às quais não existem evidências suficientes para apoiar e que devem ser utilizadas com cautela até que mais pesquisas esclareçam a questão; d) pr áticas freqüentes usadas de modo inadequado.

\section{Trajetória metodológica}

Tendo em vista a qualidade do objeto investigado, o estudo foi desenvolvido por meio de aborda gem qualitativa, especificamente na ori entação de "estu do de caso" que, segundo Merrian apud Bogdan \& Biklen (1994), consiste na observação detalhada de um con texto.

A modalidade de pesquisa qualitativa é adequ ada para estudar situações sociais que envolvem a complexidade das expressões humanas, verbais e não verbais, ten do como foco, em especial, con h ecer e com preen der os seus significados e processos de construção, contando com a participação direta desses atores (Minayo, 2000; Bogdan \& Biklen, 1994; Patrício, 1995).

Todo o processo de levantamento, regis tro, análise e devolução dos dados foi guiado por princípios éti cos que ori entam a pesquisa com sereshumanos, seguin doare so lução 196/96 do Conselho Nacional de Saúde, complementada por componen tes do processo de cuidar que costumam aperfeiçoar a interação de seres humanos, mas manten do o ri gor do método estabelecido na pesquisa. Assim, o projeto de pesquisa foi aprovado pela Comissão de Ética da Univers i d ade do Sul de Santa Catarina. 
O estudo foi desenvolvido com 11 parturientes em situação de trabalho de parto, 11 acompanhantes, 11 recém-nascidos e 10 profissionais que trabalham no centro obstétrico, sen do eles: auxiliar de en ferm a gem, en ferm ei ro obstétrico e médico ob s té tri co.

As parturien tes foram selecionadas seguindo estes critérios: ser, preferencialmente, multigesta e ter pari do neste hospital; ter acompanhante em todo o processo; não estar em fra n co trabalho de parto ; a presentar condições dínicas; dem on strar disponibilidade e interesse em participar da pesquisa; e con cordar em assinar o termo de consentimen to livre e escl a recido.

Os procedimentos metodológicos foram sis temati zados segun do con cepções de Mi n ayo (2000) e Patrício (1999), em três fases inter- relacionadas, a saber: a) fase exploratória; b) processo de coleta, registro e análise dos resultados; c) análise final e divulgação dos resultados.

A coleta de dados foi desenvolvida por meio das técnicas de observação participante, entrevista e análise documental, para complementação de dados. A observação participante, que teve como objetivo captar todo o processo da assistência à parturiente no centro obstétrico, foi desenvolvida em vários momentos e em turnos de trabalho diferen tes.

A en trevista foi realizada com as partu rientes, seus familiares e com os trabalhadores da equipe de saúde envolvidos no processo de parturição, com apoio de questões semi-estuturadas, com base também na análise dos registros de ob s ervação da assistência.

A análise documental, processada durante a observação participante, foi focalizada nos registros referentes aos atendimentos prestados, os quais, em sua maioria, compunham o prontuário da parturiente. Todos esses dados foram registrados no diário de campo, con forme Patrício (1995), com pon do notas de campo e notas da pesquisadora.

Conforme preconizado na abord agem qualitativa, a análise dos dados realizou-se durante o processo de levantamento dos mesmos, focalizando-se a assistência prestada à parturiente, ao recém-nascido e ao acompanhante, buscando-se a sintonia com as categorias pres en tes no referencial doMinistério da Sa ú depara o parto humanizado.

Seg u in do-se os princípios preconizados pela ética do estudo, o processo de saída de campo, além daquele que ocorria em cada interação com os sujeitos, c a racterizou-se pelos agradecimen tos finais e pela devolução (divulga- ção) dos re sult ados à In stituição na qual foi des envo lvida a pesquisa.

\section{Condições con cretas e em potencial para as práticas do parto humanizado}

O hospital no qual foi desenvolvido o estu do é considerado de grande porte. Trata-se de uma entidade filantrópica mantida com recursos provenientes do SUS e outros convênios, e, também, com don a tivos proceden tes da comunidade em geral. Conta com parcerias com entidades voluntárias, como, por exemplo: Pas toral da Saúde, Pastoral da Criança e Associação das Voluntá rias da Ma ternidade (Avoma), além de se caracterizar como um hospital-escola, receben do alunos de graduação e de pós-graduação da área da saúde.

O centro obstétrico desse hospital é referência regional à gestante de alto risco; em 2000 recebeu o título Hospital Amigo da Criança, con ced i dopeloMinistério da Sa ú de às insti tu ições que estão em sintonia com a redução da mortalidade materno-infantil por ações de incen tivo ao alei t a m en tomaterno que redu zem o desmame precoce.

\section{As condições do cen tro obstétri co para o parto humanizado}

A estrutura física do centro obstétrico em questão preen che requisitos necessários ao atendi$\mathrm{m}$ en to da mulh er em trabalho de parto. En tretanto, os profissionais que cumprem 12 horas de trabalho não dispõem de espaço físico para o seu descanso de uma hora, obrigando-se a ocupar o espaço da cantina e outros locais do hospital situ ados fora do cen tro obstétri co, para restabelecer suas en ergias e voltar ao trabalho. Além da questão rel a tiva à saúde do trabalhador, esse fato dificulta o atendimento às situações emergenciais que requeiram sua pres ença na unidade de trabalho.

Durante o ano de 2003 a modalidade de parto cesariano foi praticada nesta Instituição em percentual superior ao recom endado pelo Ministério da Saúde (10 a 15\%), totalizando 52,02\%. Con forme salienta Pinhei ro (1999), a intervenção da Sec retaria de Assistência à Sa úde, órgão do Mnistério da Saúde, ocorreu por causa do aumen to indiscriminado do número de cesarianas. 
Nesta perspectiva, é conveniente observar que parto humanizado (...) significa um tipo de assistênciaque, indo além de bu scar o pa rto normal a qualquer custo, procura resgatar a posição central da mulher no processo de nascimento; uma assistência que respeita a dignidade das mulheres está na sua autonomia e seu controle sob re a situação (Pel et al. apud Rede Nacional Feminista de Saúde e Direitos Reprodutivos, 2002).

Os programas de capacitação dos funcion ários adotados pelo hospital ainda são carentes de conteúdos nessa temática. Os encontros mensais têm horário restri to e, geralmente, os assu $n$ tos tra $\mathrm{t}$ ados são mais relacionados à ad $\mathrm{m}$ inistração e ao geren cia men to de ro tinas do que à qu a li idadeda assistência propri a m en te dita.

Nos con tex tos de "transmitir conhecimento", muitas ve zes a questão mais importante é a forma e não o con teú do. A prá tica do parto humanizado su gere o desenvo lvim en to da pessoa do profissional e isso implica "Sensibilizar e capacitar profissionais para o atendimento de mulheres em situação de fragilidade emocional" (Brasil, 2003).

Obj etivando a assistência com en foque humanizado, a administração da Ins ti tuição bu scou implantar cinco programas no cen tro ob stétrico, os quais foram analisados nesta pesqu isa: Programa Mãe-Canguru, no qual o recémnascido internado no Setor Intermediário à UTI permanece por tempo determinado em con ta to pele a pele com sua mãe, no Al ojamento Conjunto; Programa ABC do acompanhante, ainda não aplicado no Centro Obstétrico; Programa Encantando o diente, que, segundo os funcionários que participaram, apresenta proposta rel evante; Programa Humanização da AssistênciaHo spitalar, rel a tivamente novo, está sendo agora difundido em todos os setores do hospital, com boa receptividade pelos funcionários; Programa Vida Nova, que visa melhorar a qualidade de vida dos profissionais da Instituição.

De acordo com a ch efia do cen tro obstétrico, esses programas, mesmo ainda em fase de implantação, já apre sentam respostas satisfatórias às expectativas organizacionais, como o en gajamento de seus colaboradores no espíri to de equipe, con tribuindo no andamen to das ativid ades e na efetiva re solução de probl emas intra-organizacionais. Da participação dos funcionários nesses programas é esperada mudança de atitude que possa se reverter em melhor qualidade na assistência à população.

\section{Dos con cei tos às práticas do parto humanizado}

Na percepção dos profissionais da equipe de saúde, parto humanizado envolve relacionamen to e comunicação interpessoal, tendo em vista que "são el em en tos importantes" t a n tono processo administrativo de trabalho quan to na assistência propriamente dita. Nes te con tex to, o simples ato de "o uvir a parturien te e a sua família" e de "orientá-los sobre os procedimentos" representa condição para o parto humaniz ado. "É sermos mais humanos, tratan do a ge stante com carinho, pois para nós parir é normal, para elas é novidade"; "temos que tratar a parturiente sempre como se fosse a primeira vez, orientando sobre todos os passos pelos quais irá passar".

$\mathrm{Na}$ imagem geral que se faz de uma assistência humanizada, a comunicação com a população é um meio para a equipe de saúde captar necessidades, anseios, temores e dúvidas. Isso possibilita que se prom ova atenuação de sintomas que possam desfavorecer o processo e s eus resultados no bem-estar e segurança da parturiente, do acompanhante e também do bebê que está ch egando.

Segundo o Mnistério da Saúde, é pela comunicação que o sentim en to empático en tre o profissional e a parturien te pode se manifestar. Assim, o tipo de relacionamen to que se constrói no processo de trabalho no centro obstétrico poderá sinalizar, para o parto humanizado, $\mathrm{o}$ que para alguns dos profissionais deve demonstrar compreensão com os sentimentos que afloram nesse momento. $\mathrm{E}$ isso exige a expressão de "empatia e de tratamento carinhoso."

Parto humanizado, na con cepção dos profissionais da equipe, também deve expressar atenção à individualidade da mulher, considerando seus padrões culturais e sentimentos (suas crenças, práticas e seus valores): "É respeitar a individualidade da parturiente, promoven do o parto normal, seguindo as ori entações do Mnistério da Saúde".

A parturiente não pode ser considerada apenas uma clien te a mais. Ele deve ser compreendida em toda a sua singularidade, cabendo ao profissional de saúde, no momen to em que tenha com ela o primeiro con ta to, bem como com a sua família, con h ecer o que eles trazem de experiência. (Santos apud Oliveira et al., 2001).

A participação do acompanhante no processo de parir foi outro compon en te apontado 
pelos profissionais para caracterizar humanização no parto: "Diz res peito à presença de familiar ju n to da parturiente, desde o momento em que ela entra em trabalho de parto, permiti n do e prom oven do que o mesmo participe do processo de nascer"; "É deixar que alguém da família fique jun to da parturiente, desde o primeiro momen to"; "É colaborar para que o acompanhante ajude no parto e manifeste o seu $\mathrm{c}$ a rinho à parturien te".

(...) a presença de acompanhante contribui pa ra a melhoria dos indicadores de saúde e do bem-estar da mãe e do recém-nascido. A pre sença do acompanhante aumenta a satisfação da mulher e reduz significativamente o percentual das cesáreas, a duração do trabalho de parto (Hotimsky apud Rede Nacional Feminista de Sa ú de e Di rei tos Reprodutivos, 2002).

$\mathrm{Na}$ con cepção das parturientes, "parto humanizad" implica o fato de o profissional "ser acolhedor e ter carinho pela parturiente", e também, o "envolvim en to de mais pessoas (família)". No geral, "parto humanizado" diz respei to ao "a ten der bem a parturiente".

A definição de "partohu manizado", na concepção dos acompanhantes, não é explícita. "Nunca ouvi falar" é a ex pressão que caracteriza a percepção dessa população. Entretanto, implicitamente, respostas do tipo "são tantas as emoções que me apeguei a Deu s" mostram, de certa forma, o significado cultural-afetivo da presença do acompanhante no processo de parturição.

Se for adequado afirmar que "falar a mesma língua facilita a comunicação", ou seja, se há uma certa sintonia entre os significados da equipe de saúde e das parturientes e seus acompanhantes sobre "parto humanizado", é possível esperar que a assistência naqu ele contex to ex pressasse esse atributo, pelo menos teoricamente.

Olhando as práticas desenvolvidas pelos profissionais, sob o pon to de vista do Mnistério da Saúde, percebe-se uma variedade de expressões que mostram os atributos que compõem a qualidade da assistência prestada à mulherparturiente.

"Só prestamos cuidado para a gestante na hora do parto"; "Não nos preocupamos com a parturiente só com o momento do parto"; "O mai or con ta toésó na hora do prep a ro e na hora do parto"; "O atendimen to ao recém-nascido é ótimo, prestamos boa assistência. Eu mostro o bebê para o pai e deixo ele ver de perto o banho".
A presença do acompanhante não era permitida em todos os plantões. Uns aceitam, o utros não. Das 11 mulh eres pesquisadas, apenas três tiveram permissão para a entrada de acompanhante na sala de partos. A aceitação dessa prescrição do Ministério da Saúde, naquele contex to, fica à mercê da decisão dos profissionais.

O Ministério da Saúde pontua que a mulher e seu acompanhante devem ser prep a rados para o momento do parto, sendo que "(...) o obj etivo principal do prepa ro da mulher e seu acompanhante é favorecer que o trabalho de parto e parto sejam vivenciados com mais tranqüilidadee participação, re sgatan doo nascimento como um momento da família." (Brasil, 2001). A companhia do acompanhante (familiar ou amigo) pode não somen te auxiliar a mulher a relaxar, mas também con tribuir para que o serviço pre st ado seja mais hu manizadb.

Segundo integra $n$ tes da equipe, em bora haja por parte de alguns desses estímulos para a participação efetiva do acompanhante em todo o processo de assistir a mulher, isso nem sempre ocorre em razão de limites coloc ados por profissionais médicos e ro tinas da Instituição.

No caso do profissional médico, ele concentra a autoridade na equipe e rege os procedimentos. Talvez por chegar normalmen te ao cenário do parto sem mui to tem po para outras cenas, além daquela restrita ao momen to da parturição, tenha dificuldade de aceitar o acompanhante.

Quantoà Instituição, é ela qu em pad roniza as ações ou legitima as ro tinas construídas pelos profissionais ao longo dos anos. Muitos desses, mesmo dispondo de competência técnica e auton omia legal para o desempenho da função de atender a parturiente, ficam privados desse direi to- ou dever - porque estão vinculados a uma rotina organizacional na qual a atitude de aceitação e passividade é historicamen te aceita - às ve zes exigida - na ori entação de decisões e ações na assistência à população.

Em relação à assistência prestada ao recémnascido, o estudo evidenciou uma questão que exige especial atenção: "O pediatra presta os primeiros cuidados ao recém-nascido quando ch ega a tem po de assistir ao nascimen to"; "Não estamos preparados para avaliar as condições fisiológicas do bebê".

Essas expressões, validadas na observação participante, apontam para ausências do pediatra na equipe. Tal situação gera impasses nos demais mem bros da equipe de saúde, pois 
os cuidados que deveriam ser desenvolvidos pelo médico pediatra são assumidos pelos profissionais da en fermagem, cuja maioria entende que esse compromisso não é seu, mas o assume por "con si deração à criança."

Dado ao fato de o médico pediatra atuar também em outros setores da Insti tuição e, qu ase sempre, também ficar sob sua responsabilidade a assistência ao recém-nascido jun to do centro obstétri co, por vezes há impedimentos que não lhe permitem chegar a tempo de acompanhar o nascimen to.

De certa forma, esse fato caracteriza um problema administrativo e que não deveria se refletir na qualidade da assistência pre st ad a. No entanto é conveniente ponderar que, em última análise, a responsabilidade direta é do profissional, pos to que ele se com prom eteu em assumir a função de assistir ao recém-nascido. Por outro lado, cabe à In s ti tuição rever essa situação, no senti do de observar e adotar medidas que efetiva m en te prom ovam o que deve ser fei to.

Das 11 crianças observadas durante o processo inve sti ga tivo, apenas três foram apre sent adas à mãe logo após o parto, o que con traria as ações preconizadas pelo Ministério da Saúde, segundo o qual o contato entre mãe e recém-nascidodeve ser precoce: "O que eu ach ei de diferen te foi o fato de ter meu bebê próximo de mim".

O contato cutâneo precoce e direto entre mãe e bebê evi dencia-se como ge s to importante na atenção à saúde da criança e da mãe. Ne ste sen ti do, oMinistério da Saúde refere ser esse tipo de ação é uma das práticas demonstradamen te úteis e que devem ser estimuladas.

Por outro lado, todos os recém-nascidos foram levados posteriormente às mães, para serem amamentados. Todas foram orientadas e auxiliadas nesse processo, con forme preconiza o Programa Hospital Ami go da Criança, título que a In s ti tuição já recebeu.

Sob o olhar do nascer saudável, é importan temanter logo após o nascimen to o vínculo a fetivo entre a mãe, en tre o filho e demais membros da família. O Ministério da Sa ú de pontua: "na assistência ao recém-nascido normal, que constitui a maioria das situações, nada mais deve ser fei to além de enxugar, aquecer, avaliar e en tregar à mãe para um con t a to íntimo e precoce" (Brasil, 2001).

O respei to aos direi tos da mulher foi indicado pelos profissionais como elemento importantena assistência humanizada. No entan- to, as ob s ervações e a pró pria fala de alguns dos profissionais mostram que os cuidados estão sendo prestados exclusivamente na hora do parto e, mesmo assim, com limitações à quali$\mathrm{d}$ ade do que é pre s c ri to pelas diretrizes.

O Conselho Nacional dos Di rei tos da $\mathrm{Mu}-$ lh er (1997) reforça que aten der bem e transmitir calma são meios necessários à con dução do parto humanizado. Neste sen tido, o Mnistério da Saúde (Brasil, 2001) entende que (...) a atenção adequada à mulherno momen to do pa rto representa um passo indispensável pa ra garantir que ela possa exercer a maternidade com segurança e bem-estar.

Algumas das práticas que inibem a "segurança e o bem-estar", desestimuladas pelo Ministério da Saúde, ainda estão sendo praticadas rotineiramente no local do estu do. Dentre estas constam: in dução à trico tomia; lavagem intestinal; exame de toque vaginal (realizado várias vezes por profissionais diferentes); imobilização; posição horizontal durante o trabalho de parto; utilização do soro com o objetivo de puncionar a veia, para facilitar a posterior administração de medicamentos; administração de ocitocina para acel erar o trabalho de parto; episiotomia e a manobra de kristeller (pressão no fundo do útero duran te o trabalho de parto). Outra prática não recom en dada e que ainda é ro tina naquele cen tro obstétrico, é a ad ministração de metergim no quarto período do parto. Mais importante ainda, na perspectiva da humanização, é que dentre as parturientes, três delas não foram comunicadas a respei to do uso desse medicamento.

"O uso indevi do da episiotomia e da posteri or sutu ra (episiorrafia) é um exemplo de violação do direito de estar livre de tratamentos cruéis, humilhantes e degradantes" (Rezen de apud Rede Nacional Feminista de Saúde, Direitos Sexuais e Direitos Reprodutivo s, 2002).

A manobra de kristell er é recon hecidamente danosa à saúde e, ao mesmo tem po, ineficaz, causando à parturiente o desconforto da dor provocada e também o trauma que se seguirá indefinidamente (Brasil, 2001).

As condutas desnecessárias e arriscadas são consideradas violações ao direito da mulher à sua integridade corporal. A imposição autoritária e não info rmada desses procedimen tos atenta contra o direito à condição de pessoa (Ol iveira apud Rede Nac i onal Feminista de Saúde, Direitos Sexuais e Direitos Reprodutivos, 2002).

As puérperas, ao serem interrogadas sobre o que acharam da assistência, costumavam ava- 
liar como "boa". Ho uve qu eixa con tra a proibição de tomar líqui do. Con forme observado no cen tro obsté tri co, é ro tina não oferecer líqui do de s de o momen to de sua ch egada até a alta.

Os líquidos durante o trabalho de parto e parto podem ser oferecidos em doses moderadas. As parturien tes consideradas de baixo risco podem ingerir pequ enas quantidades de café, chá, água, su co de frutas, utilizando-se o bom senso.

Impedir generalizadamen te a ingestão de líquidos fere os precei tos do partohumanizado precon i zados pelo Mnistério da Saúde (2000), porque a ingestão de líquido, na maioria das situações, não altera o processo de trabalho de parto.

De $\mathrm{s}$ favorecendo ainda mais a condição parturien te em cenário não "humanizado", verificou-se que a mulher era deixada sozinha em a mbien te isolado, resultando, por conta disso e da própria evolução do parto, expressões de cansaço excessio, medo, tensão e dor.

En tre os fatores que aumentam a percepção da dor estão o medo, o estresse mental, a tensão, a fadiga, o frio, a fome, a solidão, o desampa ro social e afetivo, a desinformação sobre o que está acontecen do, um meio estranho ao que se está habi tu ado e o início das con trações: "Deveria ex is tir algo para aliviar a dor".

Esse é o mom en to em que a equipe precisa prom over atitu des que con tribuam para a minimização desse quadro, como, por exemplo: estimular, além da presença do acompanhante escolhido pela mulher, o uso de técnicas alternativas, como o método de Dick-Read, de Bradley e o método de Lamaze. Tais métodos pre ssupõem que sua utilização resulte em redução do medo, da tensão e da dor, con tribuindo para o relaxamen to, para a evolução do trabalho de parto, por meio da respiração lenta e do relaxamen to muscular.

O Ministério da Saúde (Brasil, 2001) preceitua medidas não-farmacológicas e não-invasivas para minimizar o estresse e aliviar a dor, tais como prom over ambi en te tranqüilo e exercícios respiratórios, de relaxamento e deambulação, além de banhos mornos e massagens, que podem ser re alizadas por familiares e/ou profissionais.

Verificou-se que, enquan to as mulheres expressavam desespero, os profissionais tentavam obedecer as rotinas, o que impedia ou limitava mais ainda a participação da mulher; por conseguinte, isso gerava perda de autonomia da mulher, que passivam en te se submetia às pres- crições dos profissionais. Fi cou eviden te a prevalência da autoridade da equipe de saúde sobre a mulher, s obre o recém-nascido e também sobre o acompanhante.

Nas interações que ocorriam nos diferen tes processos de trabalho, a autoridade dos integrantes da equi pe se sobrepunha a qualquer sinal de atitude das mulheres e dos acompanhantes, estimulan doainda mais o mom en to de fragilidade e incertezas. Isso cos tuma fortalecer o sentimento de impotência que possa haver pela situação emer gente de parto e de estar fora de seu contex to sociocultural e afetivo. A atitude profissional diferen te desta dava sinal de ser uma postura particular, atributo daqu ele profissional, e não de representar atitu de da equ ipe. Nem mesmo por conta de obediência às diretrizes doMinistério da Saúde.

O fato de a maioria das mulh eres referir satisfação quanto à assistência recebida prenu ncia que elas não têm noção do que é assistência com a qualidade que merecem. A questão é qu e todas as mulh eres en trevistadas mostra ram dificuldades em relação ao en ten dimen to do que é parto humanizado e evidenciaram desinformação acerca de direi tos e condições de boa assistência.

Essa realidade se expressa pela pouca ou nen huma exigência no cumprimen to de seus direitos, que não são apenas rel acion ados à especificidade da parturição, mas que dizem respei to aos direi tos de qualquer cidadão que necessita, nos diversos momentos da vida, da atenção dos serviços de saúde.

Art. 196. A saúde é direito de todos e dever do Estado, garantido mediante politicas sociais e econômicas que visem à redução do risco de doença e de outros agravos e ao acesso universal e igualitário às ações e serviços pa ra sua promoção, proteção erecuperação (Brasil, 1989).

Há direitos pertin en tes ao parto humanizado que nem foram mencionados, como, por exemplo, o fato de que as mulh eres tenham assegurado: as consultas, internações, procedi$m$ en tos diagnósticos e terapêuti cos du ran te todo o processo de gestação; a satisfação de suas necessidades fisiológicas, de sua privacidade e integralidade física, e a confidencialidade de toda e qualquer informação pessoal, além de total atenção à saúde do recém-nascido.

Uma das puérperas rela tou ter ido ao hospital buscar ajuda, mas que não recebeu a atenção necessária, mesmo ten do sido atendida por diferen tes profissionais. A evolução desse processo re sul tou que o bebê nasceu "pós-termo" e 
apre sen tou complicações, necessitando ser internado na UTI Neonatal: Para mim este parto foi mu i to difícil. Não en tendo por que tive de vir cinco ve zes e, mesmo tendo ultra passado as $42 \mathrm{se-}$ manas, ninguém ligou pa ra mim. Eu já sabia que alguma coisa errada estava aco $n$ te cendo.

Es te caso não é fato exclusivo na Instituição, haja vista as estatísticas que mostram a qualidade da assistência prestada à gestante $\mathrm{e}$ que têm predisposto a morbimortalidade materno-infantil. Segundo Oliveira (apud Rede Nacional Feminista de Saúde, Di rei tos Sexuais e Direitos Reprodutivos, 2002) (...) a dificuldade no aces so ao lei to, com a peregrinação das ge stantes em busca de vagas nos hospitais, viola o direito das mulh eres à eqüidade e à assistênci $a$.

A razão pode estar na qualidade do aten dimento que é prestado à mulher no pré-natal. Neste, talvez, ainda falte dar maior importância às diretrizes do Ministério da Saúde, nas ações de prevenção da mortalidade materna e infantil. Para tanto, é preciso sensibilizar as mulh eres para a busca de atenção específica logo no início da gravidez e para a escolha do parto natu ral.

Reiterando o que o Ministério da Saúde preconiza, pode-se observar que a assistência ao pré-natal é o início de todo o processo de nascer saudável. É esse o momen to inicial no qual os profissionais de saúde deverão ensejar o atendimento humanizado, as informações e os esclarecimen tos que se fizerem necessários, para que os processos de parturição e nascimento transcorram num clima de plenitude, satisfação e, sobretudo, de realização para todos, incluin do a dos profissionais envolvidos nesse process 0 .

Entende-se que, por causa do desconhecimento das ações preconizadas pelo Mnistério da Saúde, as parturientes ficavam satisfeitas com o que estavam recebendo. Se, ao contrário, as mulheres estivessem cientes de seus direitos e com seu sen ti do críti co estimulado, talvez fossem mais exigentes, menos passivas, mais atuantes e menos dominadas. Por conseguinte, as cobranças também seriam muito mais acen tu adas do que aquelas discretas en sejadas, ob s ervadas no cenário de s teestu do.

Como esperança de mudança, há o discurso de alguns profissionais da equipe de saúde que, qua ndo avaliam a qualid ade da assistência prestada naquela unidade, consideram haver necessidade de revisão de algumas práticas des envo lvidas pela equipe, dem onstra $\mathrm{n}$ do conhecimento sobre o que é prescrito para o parto humanizado: "Buscamos tratar bem a parturiente e o acompanhante, com respeito à individualidade de cada pessoa"; "A assistência prestada é boa, no entan to precisamos melhorar no sentido de nos aproximar mais da gestante e de sua família"; "Em nosso plantão, o acompanhante é bem tratado, se bem que isso não depende só da equipe de en ferm a gem, mas também dos médicos e da instituição”.

\section{A prática do parto humanizado como questão de cidadania}

Promover o parto mais humanizado nesse mundo con temporâneo é um grande desafio. Isso não requer voltar à história de como nossas avós e mães pariram, mas buscar con tribuir para que essa experiência, an tes tão natural, s eja no con tex to extradomiciliar um ritual mais próximo do "familiar", integrando nesse processo de parir e nascer os rec u rsos tecnológicos e de competência humano-científica, aos quais a mulher e seu recém-nascido têm direi to. Aum entar o con forto e a seg u rança integral dessa população é estar prom oven do a saúde da população em geral.

$\mathrm{Na}$ tentativa de fazer uma síntese para respon der à questão da pesquisa: "Como as ações preconizadas pelo Ministério da Saúde para o parto humanizado são aplicadas à parturiente, s eu acompanhante e recém-nascido?" A primeira imagem que se apresenta mostra uma dinâmica de interações mecânicas en tre trabalhadores e população, lon ge daquela imagem que se elabora ao analisar os critérios estabelecidos pelo Mnistério da Saúde.

A assistência que se en contra expressa, em grande parte, em cuidados específicos aplicados nos processos de cuidar de ro tina na atenção à parturien te focalizada no momen to do parto, no ato fisiológico de parir. Além do que algumas dessas intervenções não aten dem aos critérios de qualidade exigi dos para garantir a seg u rança da parturiente e do recém-nascido.

As imagens da assistência representam, em parte, um movimen to de rotina prescrito a qualqu er mulher, s em con si derar sua iden tidade própria e ainda muito distante da integração harmônica entre a utilização dos recursos tecnológicos e da aplicação das rotinas de trabalho da unidade, com os componen tes culturais e afetivos da mulh er e seu acompanhante, a ponto de criar, em cooperação, um ritual do processo de parir e de nascer com identidade própria. 
Na con cepção de parto humanizado, o respei to à individualidade se reve s te de importância dupla por envo lver seres que necessitam de a tenção especial, num mom en to ímpar de suas vidas e, talvez, decisivo para a promoção da sua saúdefutura. Receber cuidados para parir com segurança e con forto e para nascer com maior segurança e conforto é proporci onar melhores m eios para que ambos - mãe e filho - possam trabalhar com cuidado essa missão natural.

Na compreensão do que seja cuidado humano, essa atitude referida parece não exigir mu i to do profissional, porque a atenção à mulher nesse con texto estaria se caracterizando como um ti po de cuidado que se espera encontrar em qualqu er assistência: cuidado humanizado. Segundo Patrício (1995), cuidar é cultivar a vida e, sen do assim, toda atenção à saúde requer um processo de cuidar com cuidado care-caring, segundo Leininger (1984) - o que exige do profissional a promoção de interações baseadas em com pon en tes éti cos e estéti cos de cuidar da vida, integra ndo, assim, razão e sensibilidade nos procedimentos técnicos de ro tina e ainda favorecen do movim en tos de educação focados na participação da população envo lvida com seus saberes próprios.

Entende-se que a cultu ra do cuidado, especialmente com a qualidade "humanizado", não tem ex pressão significativa no ensino médico, tanto qua n to os padrões técnicos e a utilização da tecnologia. Entretan to, como mostra o estudo de Grosseman e Patrício (2004), existe um movimento de insatisfação entre profissionais dessa área gera n docon tradições e já estimulando diálogos com vistas à transformação dessa realidade.

Especificamente, no contexto da parturição, cuidados simples - como escutar, demons trar a tenção, atitu de - além de prom over o bem-estar e con forto das pessoas envolvidas, fortalece os direitos da mulher em trabalho de parto, con tribuin do para que ela se desenvolva como a gen te promotor de sua própria vida e da vida de seu filho. Ta lvez, o profissional desconheça isso, mas esse "simples" cuidado confere melhorqualid ade à sua assistência e ainda promove a saúde integral das pessoas.

Uma ação simples do profissional de saúde nesse momen to seria, logo no pri m ei rocontato com a parturiente, bem como com a família, indagar sobre suas repres entações a re s pei to do parto, seus temores e experiências, que poderão contribuir no processo de trabalho da equipe.
Também e preciso considerar as dificuldades apontadas pelos trabalhadores para justificar a limitação que têm em dar maior atenção à mulher e ao seu acompanhante. Algumas dificuldades se referem ao "tempo" maior que exige a assistência humanizada e que eles não dispõem em razão do reduzido número de profissionais na equipe e também por circunstâncias de acúmulo de partos em certas ocasiões, além da costumeira "falta de material".

Esta é uma realidade comum em outros serviços de assistência hospitalar, mas entende-se que a atitude humanizada dos profissionais que assistem a parturiente não está ligada exclusivamente ao tempo e ao material disponível, mas sim em tornar o mom ento dos conta tos diretos e indiretos com a população uma ex pressão de in teração de humanos que prom ova mom en tos saudáveis com a mulher, seu recém-nascido e acompanhante e, naturalmente, com os próprios integrantes da equipe de saúde.

Esses, por sua vez, como trabalh adores, também necessitam de cuidados humanizados por parte da Instituição e dos colegas, nas relações in ternas do processo de trabalho coletivo. Haja vista as limitações físicas, cogni tivas e afetivas que se ex pressam em suas condições de trabalho e que, de certa forma, pouco subsidiam e esti mulam para prestar assistência humanizada à população.

O discurso dos participantes e a análise dos registros das ob s ervações à luz das ações preconizadas pelo Ministério da Saúde mostraram que no con tex to em estudo falta ainda muito para a aplicação efetiva daqu elas ações preconizadas, s eja por conta do desconhecimen to da equipe acerca das diretrizes, seja por não estarem ainda sensibilizados para a importância da pr á tica na promoção da saúde e, talvez, por não recon h ecerem isto como um dever profissional e um direi to das mulheres.

$\mathrm{E}$, ainda, refor ça n do essa realidade, exis te a fragilidade da população que não cobra seus direitos, fortalecen do ainda mais as atitudes das equi ipes de saúde e das instituições.

Entende-se que os direitos e deveres no processo de partu rição precisam ser mais bem trabalhados naquele con texto, pos to que, ambos, população e equipe, ainda necessitam de conhecimen tos e com preensão acerca das diretrizes que promovem o parto humanizado.

Isso não se inicia no cen tro obstétri co, mas em qualquer con tex to no qual se apresentem questões de parir e nascer saudável, em especial nas unidades de atenção básica da saúde 
pública e demais espaços ambulatoriais; em âmbi to de atenção individual - e neste entende-se a mulher e seu companheiro, no mínimo - ; e em âmbi to de trabalhos de gru po, também envo lvendo não apenas as mulheres, mas familiares e demais interessados no tema.

A humanização da assistência perpassa, seguramente, pela qualidade da assistência prestada no pré-natal: pelo envolvimento da mulher, sua família e demais acompanhantes, no processo de gestar e parir, talvez, an tes mesmo da concepção, consideran do suas limitações e po ten cialid ades biológicas, socioc ul tu rais e afe-

\section{Colaboradores}

AE Reis e ZM Patrício participarm igualmen te de todas as etapas da elaboração do artigo.

\section{Referências bibliográficas}

Bodgan R \& Bicklen S 1994. Investigação qualitativa em educação. Ed. Porto, Porto.

Brasil. Mnistério da Sa ú de / Febra sgo/Aben fo 2001. Pa rto, aborto e puerpério: assistência humanizadaà mulher. Brasília.

Brasil. Ministéro da Saúde 2004. Estratégias pa ra redução de partos cirúrgicos. Disponível em: $<\mathrm{http}: / /$ saude. gov.br/datasus $>$. Acesso em 5 de janeiro de 2004.

Conselho Nacional dos Di rei tos da Mulh er 2002. Direitos damulher. Disponível em <http://www.mne.gorbr/ cdbrasil/itamaraty. web/port/relext/mne/agintern/ clmulher/apresent.> Acesso em 20 de agosto de 2002.

Conselho Nacional dos Di rei tos da Mulher 1997. Estratégias da igualdade, pl a ta fo rma de ação pa ra imple mentar os compromissos assumidos pelo Brasil na IV Conferência Mundial daMulher. Ed. ConselhoNacion al dos Direitos da Mulher, Brasília.

Grosseman S \& Patrício ZM 2004. Do desejo á realidade de ser médico - a educação e a prática médica como um processo de construção individual e coletiva. Ed. UFSC.

Lein inger M 1984. Care the essen ce of nu rsing and health. Ed. Wiley \& Sons, New York.

Min ayo MCS 2000. O desafio do conhecimento: pesquisa qualitativa em saúde. Hucitec, São Paulo. tivas para conceber; pela promoção de ações que aumen tem a compreensão dessa população sobre esse processo, considerando a integração de seus saberes com os saberes científicos da equi pe de saúde.

Para tanto, é necessário também envolver os profissionais de saúde nesse processo de aprendizagem a pon to de esti mulá-los ao retorno ao parto mais natural possível, agora com maior segurança, con siderando o apoio de toda a tecnologia que se dispõe e que também é de dever oferecer a toda a mulher em trabalho de parto e ao recém-nascido, quando necessário.
Ol ivei ra J (or g.) 1995. Constitu ição da Rep ública Fed era tiva do Brasil; atualizada e acompanhada dos textos das Emendas Constitucionais. 11. ed. atual. e ampl. Ed. Saraiva, São Paulo.

Patrício ZM 1995. A dimensão felicidade - pra zer no processo de viver saudável: uma questão bioética numa abordagen holístico-ecológica. Tese de do utorado em filosofia da saúde/en fermagem. Centro de Ciências da Saúde, Universidade Federal de Santa Catarina, Florianópolis.

Patrício ZM 1999. Qualidade de vida do ser humano na pers pectiva de novos paradigmas: possibilidades éticas e estéticas nas interações ser humano-naturezacotidiano-socied ade, pp. 19-88. In ZM Patrício, MF Araújo (orgs.) et al. Qualid ade de vida do trabalhador. uma abordagem qualitativa do ser humano através de novos paradigmas. Ed. do autor, Florianópolis.

Pinh eiroR1999. Assistência perinatal e neonatal no Brasil: um desafio para os serviços de saúde . Revista Tema 17(4):21-25.

Rede Nacional Feminista de Sa ú dee Di rei tos Reprodutivos 2002. Mortal id adematerna: Brasil, um dos campeões em mortalidade materna. Redesaúde, São Paulo.

Re zen de JD \& Mon tenegro CAB 1994. Ob stetrícia fundamental. Ed. Guanabara Koogan, Rio de Janeiro.

Artigo apre s en tado em 20/01/2004

Aprovado em 8/03/2005

Versão final apre sentada em 10/05/2005 